\title{
Using Multi-temporal RS Image and Landscape Metrics to Map Urbanization Process
}

\author{
Yang Yetao ${ }^{1} *$, Wang Yingying ${ }^{2}$ \\ ${ }^{1}$ Institute of Geophysics and Geomatics, China University of Geosciences, China \\ ${ }^{2}$ Hubei Provincial Bureau of Meteorology, China \\ *Corresponding author, e-mail: yetao.yang@gmail.com
}

\begin{abstract}
Multi-temporal remote sensing imagery is widely used to map the urbanization-caused landuse temporal dynamics, which mainly appears as built-up growth. Remote sensing integrated with landscape metrics is also used to quantitatively describe the landscape pattern of the urban area in recent literatures. In this study, we propose a grid-based framework to quantitively map the land development stage in the urban area. Remote sensing classification method is used to obtain thematic landuse maps. Built-up growth is then extracted from the multitemporal classification results by post-classification change detection. Landscape pattern, which is quantitatively described by landscape metrics, is derived from the thematic landuse maps. A grid-based method is used to analyze the land development stage based on landscape pattern and built-up growth. Finally, the development stage and its temporal changes are mapped.
\end{abstract}

Keywords- multi-temporal remote senisng; urban sprawl; landscape metrics; grid based analysis

\section{INTRODUCTION}

Urban sprawl as a consequence of socioeconomic development under certain circumstances has increasingly become a major issue facing many metropolitan areas [1]. Remote sensing classification and change detection techniques have advantages in characterizing the spatiotemporal trends of built-up growth using multi-temporal images, and providing a basis for projecting future urbanization processes [2]. For nearly three decades, extensive research efforts have been made for urban change expansion using remotely sensed images [3].

Landscape metrics (indices) are numeric measurements that quantify spatial patterning of land cover patches, land cover classes, or entire landscape mosaics of a geographic area [4]. These metrics have long been used in landscape ecology to describe the ecologically important relationships such as connectivity and adjacency of habitat reservoirs [5]. Applied to the research fields outside of landscape ecology and across different kinds of environments, particular in urban areas, the approaches and assumptions of landscape metrics may be more generally referred to as spatial metrics [6]. Spatial or landscape metrics, in general, can be defined as quantitative indices to describe structures and patterns of a metropolitan area. Its use has become a trend in urbanization studies. Combining of remote sensing, landscape metrics and urban modeling analysis may prove a promising new tool for understanding spatiotemporal patterns of urbanization [7].

The tool of integrating remote sensing, spatial analysis and spatial metrics has emerged to be very promising for understanding the spatio-temporal patterns of urbanization. Luck and $\mathrm{Wu}$ [7] used a transect sample method to identify urbanization gradients. It demonstrated the ability to reliably quantify the spatial pattern of urbanization and precisely determine the location of the urbanization center [8].

In the metropolitan area, the land will experience different development stage during urbanization process. It changes from low-speed development exurban to rapid development suburban and finally to steady urban. Recognizing the land development stage and its temporal changes are important to understand the urbanization process. The main objects of this study are: 1) setting up a framework to recognize the development stages of the land in metropolitan area; 2) mapping the development stage spatio-temporal changes by multi-temporal RS images.

\section{METHODOLOGY}

\section{A. Principle for Recogizing Development Stage}
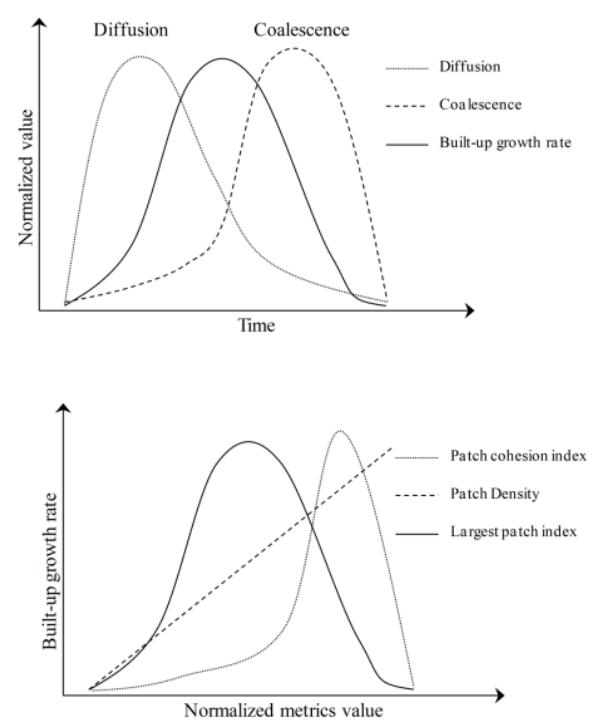

Figure 1. Theoretical signatures of landscape pattern effect on built-up growth during the full cycle of the urbanization process.

Dietzel et al's study shows that urbanization is an alternating process of diffusion and coalescence in spatiotemporal pattern [9]. The process of diffusion-coalescence indicates different development stage during the urbanization. Based on diffusion-coalescence, the built-up growth can be divided into several stages. In the early stage, the landscape is mainly occupied by homogeneous non-urban background.

Supported by the National Natural Science Foundation of China (No. 41201430), the Special Fund for Basic Scientific Research of Central Colleges China University of Geosciences (Wuhan), China. 
Built-up patches spot on this background and the speed of the built-up growth is low. In the mid stage, due to the diffusion process, the landscape gets high fragmentation with continuously appearing built-up patches. The built-up growth speeds up in this phase. In the final stage, due to the coalescence process, the built-up increase slows down. The new built-up mainly fill up the gaps between the early developed patches. A conceptual framework illustrating the hypothesis of landscape pattern effect on built-up growth is shown in figure 1 . The landscape pattern diffusion and coalescence processes can be represented by landscape metrics. The relation between metrics value and built-up growth is shown in the bottom graph of figure 1. The fragmentation index, such as patch density, shows a linear relation with the built-up growth rate. The development degree metrics, such as largest patch index and patch cohesion index of urban type, first show a positive relation and later a negative relation with the built-up growth rate. The different development stages can refers to land types. The early stage refers to exurban, middle stage to suburban and final stage to urban core.

\section{B. Data Process}

The Beijing city was chosen as the experimental area. Beijing, as the capital city of China, has been experiencing a rapid development. The built-up area expanded from $366 \mathrm{~km}^{2}$ in 1984 to $1289 \mathrm{~km}^{2}$ in 2008 (State Statistical Bureau of China, 1984, 2008), which indicates a double growth of the population and a three times growth of the built-up area in 25 years. For the past 30 years, the urban sprawl of the Beijing metropolitan area has mainly happened in three styles - around the urban center, along the transportation lines and leapfrog development. Seven Landsat images were acquired for discerning the influence of landscape pattern on the built-up expansion in this study (table 1), including four TM images acquired in 1988, 1991, 1994 and 1997, and three ETM+ images acquired in 2000, 2003 and 2006.

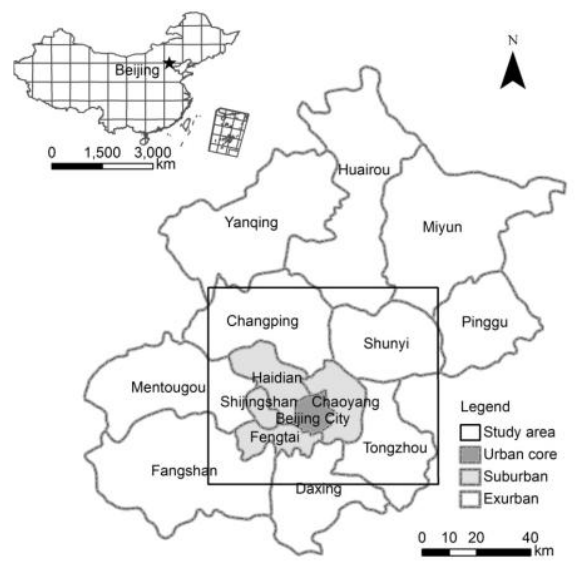

Figure 2. Study area covering Bejing metropolitan area.

To ensure that the classification of multi-source, multitemporal images can be compatible with each other, a unified land cover classification scheme was used (Table 2). The images were first classified into seven land cover types, namely water paddy, green paddy, post-harvest paddy, impervious surface, city green, woodland and water body. The initial classification results were then merged into four final classes, namely farmland, built-up area, woodland and water body.

TABLE I. DATA ACQUIRED AND STUDIED IN THIS RESEARCH.

\begin{tabular}{ccccc}
\hline Satellite & Sensor & Path/Row & $\begin{array}{c}\text { Resolution } \\
(\mathbf{m})\end{array}$ & Acquisition Date \\
\hline Landsat 5 & TM & $\mathbf{1 2 3 / 3 2}$ & 30 & 28 September 1998 \\
Landsat 5 & TM & $123 / 32$ & 30 & 6 May 1991 \\
Landsat 5 & TM & $123 / 32$ & 30 & 28 August 1994 \\
Landsat 5 & TM & $123 / 32$ & 30 & 21 September 1997 \\
Landsat 7 & ETM & $123 / 32$ & 30 & 3 April 2000 \\
Landsat 7 & ETM & $123 / 32$ & 30 & 28 July 2003 \\
Landsat 7 & ETM & $123 / 32$ & 30 & 26 September 2006 \\
\hline
\end{tabular}

TABLE II. UNIFIED LAND COVER CLASSIFICATION SCHEME.

\begin{tabular}{ccc}
\hline Level 1 classes & Level 2 classes & Description \\
\hline Farmland & $\begin{array}{c}\text { Water paddy } \\
\text { Green paddy }\end{array}$ & $\begin{array}{c}\text { Paddies inundated by water } \\
\text { Paddies with crops in green } \\
\text { status }\end{array}$ \\
Built-up area & $\begin{array}{c}\text { Post-harvest paddy } \\
\text { Impervious surface } \\
\text { City Green } \\
\text { Woodland }\end{array}$ & $\begin{array}{c}\text { Paddies with crops clear-cut } \\
\text { Construction areas } \\
\text { Parks, green belts and lawns } \\
\text { Forest on west and north, } \\
\text { Shelter belts }\end{array}$ \\
Water body & Water body & $\begin{array}{c}\text { Rivers, fish ponds and } \\
\text { reservoirs }\end{array}$ \\
\hline
\end{tabular}

To distinguish landscape pattern spatial changes, the total metropolitan area should be split into sub regions which can reserve local landscape pattern characters. In this study, landscape gradient analysis method was used to detected proper splitting size of the experimental area (Yang, 2010). The study area was split into sub grids at size of $6 \mathrm{~km} \times 6 \mathrm{~km}$. The landscape pattern was extracted by each grid for later modeling. The landscape metrics were used in this study as shown in table 3. The PD, SHDI and CONTAG are landscape level metrics. The LPI, COHESION and PLAND are class level metrics. For the class level metrics, we only calculated them for the built-up and farmland. We used Fragstats 3.3 build 5, to metrics value for each grid from 1988 to 2006. The computations were performed using the 8-cell (Queen's case) patch neighborhood rule, with the boundaries excluded.

TABLE III. LANDSCAPE METRICS DESCRIPTION

\begin{tabular}{ccc}
\hline Metrics & Abbreviation & Unit \\
\hline Patch density & PD & $\# / 100 h a$ \\
Shannon's diversity index & SHDI & none \\
Contagion & CONTAG & $\%$ \\
Largest Patch Index & LPI & $\%$ \\
Patch Cohesion Index & COHESION & $\%$ \\
Percentage of landscape & PLAND & $\%$ \\
\hline
\end{tabular}

\section{Modeling Development Degree}

According to the principal to recognize the development stage, the metrics were categorized to tree types: urban indices, rural indices and hybrid indices. With the urbanization process, the urban indices will increase, rural indices will decrease and the hybrid will first increase then decrease or first decrease then increase. For this study, the PD and CONTAG are hybrid indices. LPI, PLAND and COHESION metrics of built-up are 
urban indices. While LPI, PLAND and COHESION metrics of farmland are rural indices.

To recognize the development stage by the landscape metrics, a fuzzy method was used to determine the urbanization degree of each metric. For three types of indices, the urbanization degree calculation is different. The urban indices will increase during the urbanization process. The development degree can was calculated by the equation 1 .

$$
\mu(x)=\left\{\begin{array}{l}
0, x \leq m \\
\frac{e^{x}-e^{m}}{e^{M}-e^{m}}, m<x<M \\
1, x \geq M
\end{array}\right.
$$

Where $\mathrm{m}$ is threshold of rural and $\mathrm{M}$ is threshold of urban core.

For the rural indices, the following equation 2 was used to calculate the development degree.

$$
\mu(x)=\left\{\begin{array}{l}
1, x \leq M \\
\frac{(m-x)(m+x-2 M)}{(m-M)^{2}}, M<x<m \\
0, x \geq m
\end{array}\right.
$$

The hybrid indices can be classified into two types. PD first increases with development degree and then decreases. CONTAG first decreases with the development degree and then increases. The equation 3 and equation 4 calculate the development degree from SHDI. The way to calculate the development degree is reverse.

$$
\begin{aligned}
& \mu(x)=\left\{\begin{array}{l}
1, x \leq s_{1} \\
1-\frac{0.4\left(x-s_{1}\right)}{s_{2}-s_{1}}, s_{1}<x<s_{2} \\
0, x \geq s_{2}
\end{array}\right. \\
& \mu(x)=\left\{\begin{array}{l}
0, x \leq s_{4} \\
\frac{0.2\left(x-s_{4}\right)}{s_{3}-s_{4}}, s_{4}<x \leq s_{3} \\
0.2+\frac{0.4\left(x-s_{3}\right)}{s_{2}-s_{3}}, s_{3}<x \leq s_{2}
\end{array}\right.
\end{aligned}
$$

Where $s_{1}, s_{2}, s_{3}, s_{4}$ are thresholds for urban core, suburban, exurban and rural respectively.

The equation 5 was used to integrate the fuzzy membership of the nine metrics,

$$
U=\sum_{1}^{n} u_{i} \bullet w_{i}
$$

Where $\mu_{i}$ is the membership of $i$ th metric, $w_{i}$ is the weight of the $i$ th metric

\section{RESULTS}

\section{A. Landscape Metrics Extraction}

Figure 3 shows part of the Landscape metrics extracted from the remote sensing imagery. The results based on sub grids satisfactorily reserve the local landscape pattern characteristics and express the spatio-temporal change of the whole metropolitan area. Urban core, urban fringe and rural area can be clearly distinguished from the landscape pattern spatial changes. In PD maps, the urban core and rural area sub grids are associated with low metric values, while urban fringe sub grids are associated with high metric values. The situation is reversed in CONTAG maps with low values in the urban fringe, while high values in the urban core and rural area. LPI maps give prominence to the urban core area and COHESION maps illustrate the extent of the urban expansion influence. Spatial changes of these landscape metrics express themselves as demarcated rings centered on the urban core in the metropolitan region. Temporal changes of the landscape metrics reflect the development of the urban core and urban fringe sprawl. The boundary of the urban core extends to occupy the early urban fringe area, while the urban fringe extends to occupy the early rural area. The urban fringe of the Beijing city has enlarged obviously in the course of time, which caused the mean value of sub grids' PD, LPI and COHESION to increase, while that of CONTAG to decrease. The changes of landscape metrics reveal a fragmentation process of the Beijing city in the study period.

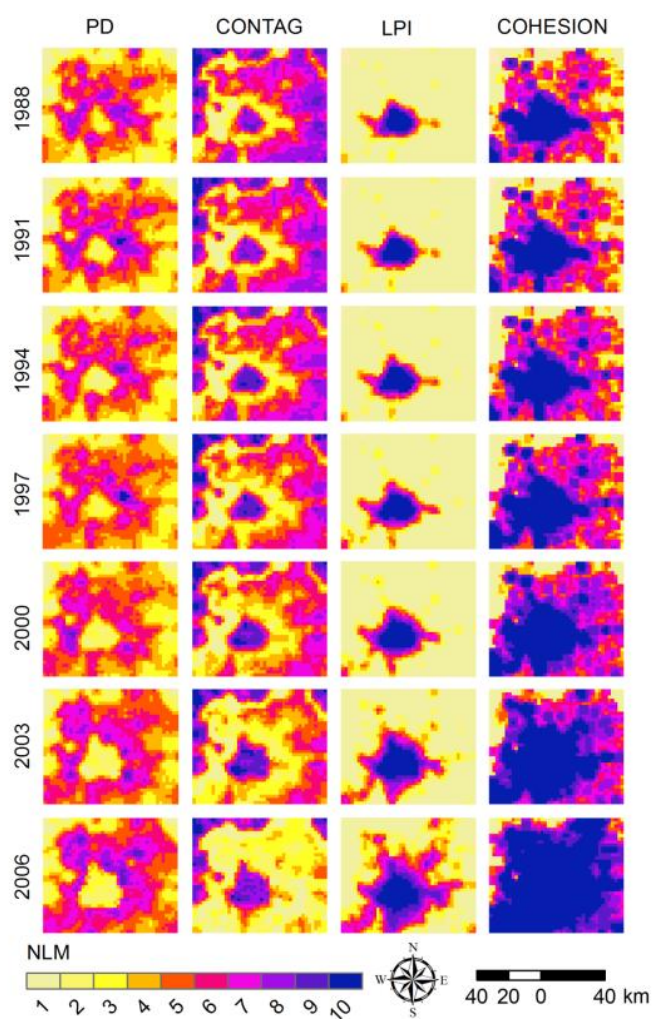

Figure 3. Part of the landscape metrics showing the spatio-temporal changes from 1988 to 2006. The pixel value is the normalized landscape metric (NLM) value calculated by Fragstats.n

\section{B. Development Stage Model}

Figure 4 shows the development stages of the Beijing metropolitan area during 1988 2006 with 3 years interval. The integrated development degree gets high value at the center of urban and gradually decreases when spreading to the exurban. It shows good hierarchical quality in spatial domain. 
With the urbanization process, the development degree increases obviously in temporal domain for all grids except the urban core grids. Especially the grids get middle development degree value increase sharply after year 2000 that makes the boundary of the suburban obscure.

The spatio-temporal changes of the development degree reflect the urbanization styles changes. The urbanization style changes from the around the urban core to around urban core coinciding with the leap-frog and axis-around. The development degree value change indicates the urbanization speeding up in the study 20 years.

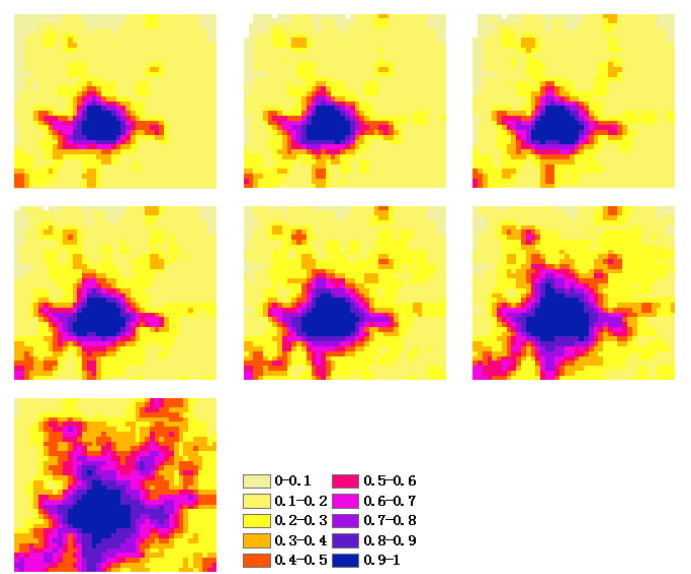

Figure 4. Devloment degree sptial-tepmoral changes during study period

\section{Temporal change mapping}

When setting thresholds on the development stage map, we can map the urban core, suburban, exurban and rural area. The thresholds we used in this study are $0.9,0.6$ and 0.3 respectively. Overlapping the crisp maps can get the urban core, suburban and exurban expansion during the study area (figure 5).

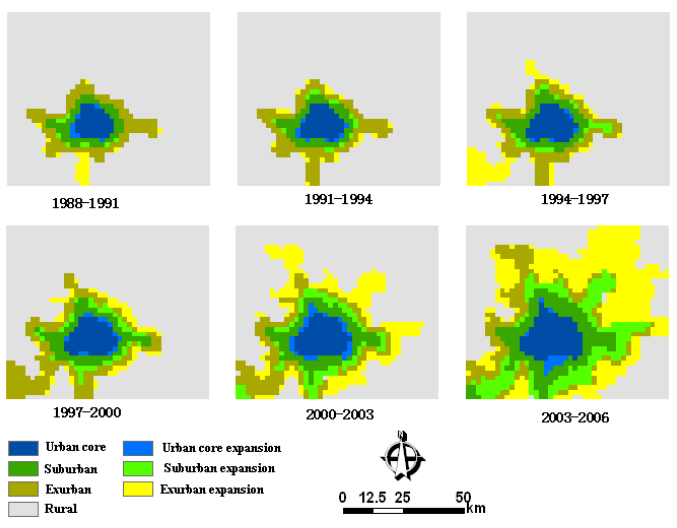

Figure 5. Temporal changes of the urban core, suburaban end exurban

The urban core area expands from $176 \mathrm{~km}^{2}$ to $440 \mathrm{~km}^{2}$ during the study period. The suburban expands from $256 \mathrm{~km}^{2}$ to $1412 \mathrm{~km}^{2}$. The exurban expands from $480 \mathrm{~km}^{2}$ to $2344 \mathrm{~km}^{2}$. The rural shrinks from $5136 \mathrm{~km}^{2}$ to $1840 \mathrm{~km}^{2}$.

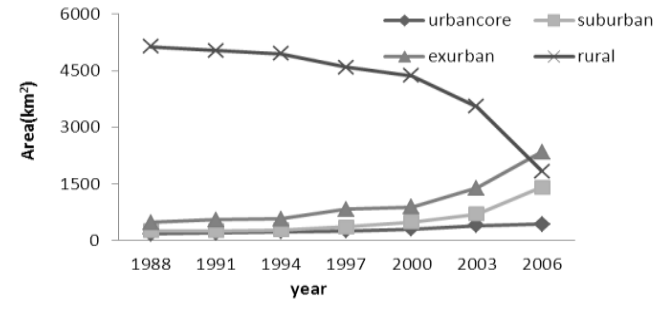

Figure 6. Area changes of the urban core, suburaban end exurban

\section{DISCUSSION \& CONCLUSIONS}

The grid based landscape pattern analysis proves the urban expansion style of the Beijing city. The urbanization process gradually changes form the around the urban core to three styles - around the urban center, along the transportation lines and leapfrog development. The urban expansion speeds up during the study period.

The grid based landscape pattern analysis well preserves the local pattern characteristics and facilitates the spatiotemporal modeling. The thresholds used to categorize the urban core, suburban, exurban and rural are subjectively selected. The turn points for the fuzzy membership calculation are also decided subjectively. The introduction subjective data in the model will demand specialist knowledge that cuts down the universal property of the framework. The further work of this study is to development method to automatically decide the model parameters.

\section{REFERENCES}

[1] N.B. Grimm, J.M. Grove, S.T.A. Pickett and C.L. Redman "Integrated approaches to long-term studies of urban ecological systems," BioScience, vol. 50 (7), 2000, pp. 571-584.

[2] B.N. Haack and A. Rafter, "Urban growth analysis and modelling in the Kathmandu valley, Nepal," Habitat International, vol. 30 (4), 2006, pp. 1056-1065.

[3] Y.T. Yang, Q.M. Zhou, J.Y. Gong and Y. Wang, "An integrated spatiotemporal classification method for urban fringe change detection analysis," International Journal of Remote Sensing, vol. 33 (8), 2012, pp. 2516-2531.

[4] M.G. Turner and R.H. Gardner (Eds.), Quantitative Methods in Landscape Ecology, 1991, New York: Springer-Verlag.

[5] C.Y. Jim and W.Y. Chen, "Diversity and distribution of landscape trees in the compact Asian city of Taipei," Applied Geography, vol. 29 (4), 2009, pp. 577-587.

[6] M. Herold, H. Couclelis and K.C. Clarke, "The role of spatial metrics in the analysis and modeling of urban change," Computers, Environment, and Urban Systems, vol. 29 (4), 2005, pp. 339-369.

[7] M. Luck and J.G. Wu, "A gradient analysis of urban landscape pattern: A case study from the Phoenix metropolitan region, Arizona, USA," Landscape Ecology, vol. 17(4), 2002, pp. 327339.

[8] M.K. Shrestha A.M. York, C.G. Boone and S. Zhang, "Land fragmentation due to rapid urbanization in the Phoenix Metropolitan Area: Analyzing the spatiotemporal patterns and drivers," Applied Geography, vol. 32 (2), 2012, pp. 522-531.

[9] C. Dietzel, M. Herold, J.J Hemphill and K.C. Clarke, "Spatiotemporal dynamics in California's central valley: Empirical links to urban theory," International Journal of Geographic Information Science, vol. 19 (2), , 2005, pp. 175-195. 